\title{
ALIMENTAÇÃO, SAÚDE E SOCIABILIDADE: A ARTE DE CONSERVAR E CONFEITAR OS FRUTOS (SÉCULOS XV-XVIII)
}

\author{
Feeding, health and sociability: the art of keeping and \\ decorating fruits ( $15^{\text {th }}-18^{\text {th }}$ centuries) \\ Leila Mezan Algranti*
}

\section{RESUMO}

Este artigo trata da simbologia e da utilidade das conservas de frutos na época moderna a partir da análise de três tratados antigos de confeitaria reeditados recentemente. Eles revelam momentos distintos sobre a produção das conservas, incluindo os conhecimentos técnicos disponíveis e sua evolução. Apresentam-se ao historiador, portanto, como fontes instigantes para a História da Alimentação do período.

Palavras-chave: conservas de frutas, confeitaria, açúcar.

\section{ABSTRACT}

Departing from three ancient texts on pastries recently republished, this article analyzes the simbology and utility of the fruit preserves in the Modern Age. These ancient texts are instigating sources for the history of cookery and eating.

Key-words: fruit preserves, pastries, sugar.

\section{Simbologia e utilidade das conservas de frutos}

O açúcar entrou no mundo pelo laboratório dos boticários, onde desempenhou um papel importante, pois, para falar de alguém a quem faltasse algo essencial, dizia-se: "é como boticário sem açúcar". ${ }^{1}$ Este comentário de

* Professora Doutora da Unicamp. 1995. p. 105

1 Cf. BRILLAT-SAVARIN, Jean Anthelme. A fisiologia do gosto. São Paulo: Cia. das Letras, 
Brillat-Savarin (século XVIII) é bastante exato, já que por muito tempo o açúcar foi considerado um produto de botica por ser usado quase sempre como medicamento. Ele tornou-se um elemento inquestionável na farmacopéia ocidental, como atestam os textos de Galeno, que iniciou uma classificação para receitas com plantas medicinais baseada nos ensinamentos de Hipócrates, criando uma tipologia própria. ${ }^{2}$

A planta e as técnicas de fabricação desse precioso produto, considerado uma especiaria rara e um poderoso componente medicinal e farmacêutico, foram levadas do Oriente para a bacia do Mediterrâneo e, posteriormente, para a Península Ibérica pelos árabes. Foram eles também os responsáveis pelo desenvolvimento de seu consumo na medicina, na culinária e na doçaria. Entretanto, foram os chineses que fizeram as primeiras experiências para transformar o sumo da cana em açúcar sólido. ${ }^{3}$ Seu uso terapêutico era indicado para suprir a insuficiência calórica por ser considerado como fortificante ou complemento alimentar. Era também aconselhado, no início da época moderna, para "confortar o estomago e os intestinos e dar boa disposição ao ventre". ${ }^{4}$

Mesmo com a expansão da produção açucareira no Mediterrâneo (Marrocos e Sicilia) e mais tarde nas ilhas do Atlântico e no Brasil, o açúcar não perderia seu tradicional valor terapêutico, que acabou sendo associado também aos demais produtos derivados da cana-de-açúcar, como o melaço e a aguardente, bem como aos alimentos fabricados com açúcar: os confeitos e os doces de frutas.

Essa associação entre alimentação e saúde é muito antiga e os cuidados com o corpo originaram numerosos tratados médicos e de caráter moral, que seguiam, muitas vezes, o famoso preceito de Hipócrates: “...dos teus alimentos farás a tua medicina". ${ }^{5}$ A alimentação teve, assim, um papel primordial na teoria de Hipócrates, já que seria a responsável pela gestão da harmonia que deveria reinar entre os humores constituintes do corpo humano. Ao longo dos séculos, contudo, o açúcar foi considerado ora um excelente

2 O uso de plantas para promover a saúde pode ser datado do tempo de Hipócrates, que, ao longo de sua vida (460-370 a.C.), compilou A matéria médica, um livro com informações sobre plantas e respectivo receituário, com mais de 400 plantas medicinais. Ver sobre o assunto: WEBB, Marcus A.; CRAZE, Richard. $O$ guia das plantas \& especiarias. Lisboa: Livros e Livros, 2000. p. 9-11; ver também: VIEIRA, Alberto. Canaviais, açúcar e aguardente na Madeira séculos XV a XX. Funchal: Centro de Estudos de História do Atlântico. p. 319.

3 NUNES, Naidea. Palavras doces - terminologia e tecnologia históricas e actuais da cultura açucareira: do Mediterrâneo ao Atlântico. Funchal: Centro de Estudos de História do Atlântico, 2003. p. 15.

4 Cf. VIEIRA, op. cit., p. 320.

5 Sobre os livros de dietética do início da época moderna ver: REVEL, Jean François. Um banquete de palavras - uma história da sensibilidade gastronômica. São Paulo: Cia. das Letras, 1996. p. 9-30. 
medicamento para restabelecer a saúde do corpo enfermo, ora um elemento a ser excluído das dietas por causar distúrbios ao corpo sadio. O seu uso deveria, portanto, ser bem dosado e combinado a fim de manter o equilíbrio necessário ao organismo. Entretanto, apesar das prescrições médicas, a difusão do consumo de açúcar, a partir do século XV, transformou o "Renascimento na era das guloseimas". Na obra Théatre de l'Univers, o geógrafo Ortelius (1572) detectou bem a mudança que estava ocorrendo em relação à utilização do açúcar ao comentar: "Enquanto antigamente só se encontrava açúcar nas boticas dos farmacêuticos que o guardavam para os doentes, hoje devoram-no por gulodice... O que ontem servia de remédio, serve hoje de gulodice". ${ }^{6}$

De fato, no universo das composições gastronômicas, o açúcar foi perdendo, ao longo da época moderna, a função que possuía, até a Idade Média, de ser apenas condimento ou especiaria, assumindo o papel de gênero básico e indispensável na alimentação. Associado a outros gêneros, o açúcar passou a gerar alimentos e sabores múltiplos.

No final do século XVIII, quando seu uso já havia feito a entrada triunfal no setor da confeitaria e doçaria, Brillat-Savarin resumiu com certa graça e habilidade o resultado da combinação do açúcar com outros produtos:

\begin{abstract}
Misturado com farinha e ovos, [o açúcar] fornece os biscoitos, os bolos, os pudins, e aquela quantidade de iguarias leves que constitui a arte bastante recente da confeitaria. Misturado com leite, fornece os cremes, os manjares-brancos e outras sobremesas que encerram agradavelmente uma refeição. Misturado às frutas e às flores, fornece as geléias, as marmeladas, as conservas, as gelatinas e os candis, o que nos permite gozar o perfume dessas frutas e dessas flores muito tempo após a época que a natureza havia fixado para sua duração. Enfim, misturado ao álcool, o açúcar fornece os licores... ${ }^{7}$
\end{abstract}

Embora Brillat-Savarin considerasse a confeitaria uma arte recente na França, em Portugal e no restante da Península Ibérica, há registros sobre o ofício de confeiteiro e conserveiro bem anteriores, datados do final da Idade Média e início da época moderna, já que a indústria de conservas ou de doces de frutas, de influência árabe, desenvolveu-se associada à produção de açúcar.

6 Apud Maria Proença, prefácio à reedição de RIBEIRO, Emanuel. $O$ doce nunca amargou... Doçaria portuguesa. História, decoração, receituário. Sintra: Colares, 1997. p. 20-21.

7 Cf. BRILLAT-SAVARIN, op. cit., p. 106. 
Nessas regiões, surgiu uma grande variedade de confeitos e doces de frutas (em calda de açúcar, cristalizadas) que eram, inclusive, exportados para outras partes da Europa.

No início, esses doces e confeitos destacaram-se pelo seu valor medicinal, mas rapidamente foram adquirindo outros usos e significados e estimularam uma indústria doceira que se expandiu rapidamente, sendo aperfeiçoada nos séculos seguintes.

Os doces passaram a ser presença obrigatória na culinária conventual e palaciana portuguesa, sendo oferecidos no último serviço de mesa. ${ }^{8}$ Ganharam espaço também nos banquetes e festins das cortes européias, cujas mesas ostentatórias repletas de confeitos de mel ou açúcar, todos diferentes, na forma de castelos, animais, flores e frutos, tornaram-se célebres. No século XVI, os "banquetes de açúcar" viraram moda nas cortes italianas e expandiram-se em direção às cortes do norte. Consistiam em imensas mesas adornadas com doces de vários tipos apresentadas aos convivas após o banquete de pratos salgados. ${ }^{9}$ Esse aspecto de celebração conferido aos doces foi conquistando espaços cada vez maiores, sendo associado às diversas festas e eventos do calendário litúrgico e laico, nas esferas pública e doméstica.

Com a expansão da produção de açúcar, o doce foi sendo introduzido também nas mesas mais populares, sempre com esse caráter supérfluo, comemorativo e de encerramento de uma boa refeição. Invadiu as merendas e as ceias frugais, adquirindo ainda uma conotação de mimo e de presente a ser ofertado como sinal de estima. Vasco da Gama, por exemplo, ofereceu ao xeque de Moçambique conservas da ilha da Madeira. ${ }^{10}$ Com o tempo, o costume tomou dimensão maior, alastrando-se pela sociedade. Assim, símbolo de status, de amor, de festa e de sociabilidade, o doce conquistou muitos significados sem perder seu valor medicinal e nutritivo original.

Embora a doçaria tenha se desenvolvido amplamente a partir do século XVII, como atestam os livros antigos de receitas com sua variedade de receitas de bolos, tortas e cremes, a arte de conservar e de confeitar frutos foi uma das primeiras a se desenvolver no setor. Os confeitos de frutas e as conservas (frutas conservadas em açúcar) eram afamados na Ilha da Madeira já no século

8 Ver sobre o assunto: SARAMAGO, Alfredo. Docaria Conventual do Alentejo - as receitas e o seu enquadramento histórico. 4. ed. Sintra: Colares, 2000; CONSIGLIERI, Carlos; ABEL, Marilia. A tradição conventual na doçaria de Lisboa. Sintra: Colares, 1999.

9 Cf. STRONG, Roy. Banquete - uma história ilustrada da culinária, dos costumes e da forma à mesa. Rio de Janciro: J. Zahar, 2004 p. 170-172.

10 Cf. VIEIRA, op. cit., p. 338. 
$\mathrm{XV}$, sendo muitas vezes enriquecidos com especiarias européias e orientais (amêndoas, anis, gengibre, coentro seco). ${ }^{11}$ As frutas cristalizadas, por sua vez, são referidas pelos viajantes que visitaram a ilha no século XVI, como informa Pompeo Arditi, em 1567, ao "mencionar que nela ancoram todos os barcos para comprar açúcar, vinho e conserva de açúcar, que nesta cidade se fazem de grande qualidade e em muita abundância". ${ }^{12}$ Nessa localidade era também famosa a "casquinha", conserva feita com a casca de frutos cítricos, a qual fazia parte da provisão das embarcações nas grandes viagens marítimas, por ajudar a combater o escorbuto. ${ }^{13}$ Sabe-se, por outro lado, que em Valência e na Sicilia havia uma tradição conserveira importante desde o início da Idade Moderna, conforme mencionou Nostradamus. ${ }^{14}$

$\mathrm{O}$ gosto e os conhecimentos técnicos para fabricar conservas com frutos tropicais foram registrados também pelos primeiros cronistas da América portuguesa, sinal de que os conquistadores preservaram, no Novo Mundo, certos saberes e hábitos alimentares europeus. ${ }^{15}$ Em Portugal, essa arte era desenvolvida domesticamente pelas mulheres, servindo de sustento a muitas famílias, mas havia também homens envolvidos no ofício, como informa a documentação portuguesa ao referir-se aos "conserveiros", "confeiteiros" e "alfoeleyros" (fabricantes de alféloas, um doce de calda de açúcar ou de melado em ponto). ${ }^{16}$ Mas foi nos conventos e recolhimentos femininos que a arte da doçaria e conservaria se expandiu, notadamente em Portugal e em suas colônias, a partir do século XVII, cujas religiosas conquistaram a fama de exímias doceiras. ${ }^{17}$ Essa tradição doceira marcou a culinária portuguesa até os dias de hoje, conferindo identidade à doçaria regional lusitana, como as queijadas de Sintra, os ovos moles de Aveiro e tantos outros doces conventuais, cujas receitas foram transmitidas através das gerações.

11 NUNES, op. cit., p. 157

12 Cf. ARAGÃO, A. A madeira vista por estrangeiros 1455-1700. Funchal: DRAC, 1981. p. 132, apud NUNES, op. cit., p. 161

13 NUNES, op. cit., p. 164

14 NOSTRADAMUS, Michel. Tratado da maneira de fazer doces de frutos. Sintra: Colares, 2002. p. 19 .

15 Cf. SOUSA, Gabriel Soares de. Tratado descritivo do Brasil em 1587. São Paulo: Cia. Editora Nacional, 1971. Título 5: "Das árvores e plantas indígenas que dão fruto que se come", p. 190-202.

16 A alféloa era um doce muito popular, resultado do açúcar posto em ponto forte, o que tornava $o$ doce muito alvo e com o qual faziam-se varetas retorcidas. Sobre o assunto, ver: NUNES, op. cit., p. 160.

17 Sobre a doçaria no Brasil, ver: ALGRANTI, Leila Mezan. Os doces na culinária luso-brasileira: da cozinha dos conventos à cozinha da casa "brasileira", séculos XVII a XIX. Anais de História de Além-Mar, Lisboa, Universidade Nova de Lisboa, 2006. No prelo. 
Quanto à divulgação da técnica de conservar, além da transmissão oral e dos cadernos de receitas dos conventos, nota-se que, de início, as receitas de doces estavam presentes nos livros de copa ou de "segredos", que traziam receitas de mezinhas, bebidas, xaropes e outras notícias de práticas domésticas. Posteriormente, foram introduzidas nos livros de cozinha, juntamente com os pratos salgados, mas acabaram por constituir um setor separado na história da edição européia na época moderna. ${ }^{18}$ Do conjunto dessas obras, selecionamos três tratados reeditados recentemente que permitem perceber os usos e os significados atribuídos aos doces de frutas, bem como avaliar os conhecimentos técnicos disponíveis entre os séculos XV e XVIII.

\section{Três tratados para conserveiros e confeiteiros}

As compilações de receitas culinárias não esperaram a invenção da imprensa, uma vez que há registros de manuscritos em diferentes países da Europa desde o início do século XIV, talvez até desde o fim do século XIII. Mas, a partir da época moderna, intensificaram-se as publicações desse tipo, embora sua grande expansão só tenha ocorrido no final do século XIX.${ }^{19}$ Essas compilações técnicas foram escritas por cozinheiros e médicos, mas também por profissionais cujos ofícios relacionavam-se à arte de receber e ao serviço de mesa, como os trinchadores, os mordomos, os provedores e os mestres de cerimônias (o scalco).$^{20}$

A arte de fazer conservas, como seu nome indica, surgiu da necessidade de conservar por uma longa temporada os frutos sazonais, a fim de evitar sua corrupção e desperdício, mantendo seus componentes nutricionais. Os três tratados escolhidos para análise revelam, porém, momentos distintos sobre a produção das conservas e seus conhecimentos na Idade Moderna, bem como algumas mudanças na forma de se contemplar a conservaria.

18 Sobre a história dos livros de cozinha, ver: HYMAN, Philip; HYMAN, Mary. Os livros de cozinha na França entre os séculos XV e XIX. In: FLANDRIN, Jean-Louis; MONTANARI, Massimo (Orgs.). História da Alimentação. São Paulo: Estação Liberdade, 1998. p. 629.

19 FLANDRIN, Jean-Louis. Os tempos modernos. In: FLANDRIN, Jean-Louis; MONTANARI, Massimo (Orgs.). História da Alimentação. São Paulo: Estação Liberdade, 1998. p. 549.

20 Roy Strong desenvolve amplamente o tema do serviço de mesa e suas transformações na época moderna utilizando uma ampla literatura da época escrita por profissionais diversos. Ver, especialmente, STRONG, op. cit., p. 113-179, o capitulo "O ritual renascentista". 
Nas Notas de cocina de Leonardo da Vinci (1452-1519), as poucas receitas de pratos doces despontam em meio às de outros pratos como testemunho dos hábitos alimentares da época ou da forma de aproveitamento dos produtos, quando os alimentos feitos com açúcar eram ainda pouco presentes na dieta cotidiana européia. ${ }^{21}$ No Tratado da maneira de fazer doces de frutos (1552), de Michel de Nostre-Dame - Nostradamus - (1503-1566), as conservas são resultado do interesse do autor no estudo das plantas e seus efeitos na cura das doenças. ${ }^{22}$ Em Arte nova e curiosa para conserveiros confeiteiros e copeiros (1788), o autor, anônimo, contempla apenas o segmento da doçaria na culinária, com ênfase nas conservas, produzindo uma obra altamente especializada, em um momento em que a confeitaria e a conservaria já haviam conquistado definitivamente seu lugar de celebração, distinção e sociabilidade na boa mesa européia. $^{23}$

Escritos com propósitos diferentes e visando públicos distintos, os três compêndios de receitas apresentam-se ao historiador como fontes instigantes para a História da Alimentação da época moderna. Como destacou Bruno Laurioux, os livros de receitas ou de cozinha são um testemunho das práticas culinárias de uma sociedade ou de um determinado segmento social, numa época específica. ${ }^{24}$ Nos estudos sobre a História da Alimentação, eles assumem papel de destaque, já que revelam não apenas certos hábitos alimentares, mas também as técnicas culinárias, os produtos e instrumentos utilizados e, fundamentalmente, as inovações e as mudanças no gosto. Vejamos então, primeiramente, as características de cada uma dessas obras para, em seguida, nos atermos às técnicas e aos procedimentos sobre a arte de conservar os frutos que elas indicam.

As Notas de cocina de Leonardo da Vinci são consideradas o resultado de uma obra ficcional, já que o suposto documento que teria permitido a compilação - o Códice Romanoff - jamais foi localizado e o que existe até hoje são especulações sobre a autoria de um manuscrito cuja cópia dataria do século XIX adquirida, possivelmente, pela nobreza russa, juntamente com outras obras de da Vinci disponíveis no Museu de Leningrado. O interesse do

21 NOTAS de cocina de Leonardo Da Vinci - la afición desconocida de um gênio. Buenos Aires: Planeta, 2001. (Temas de Hoy)

22 NOSTRADAMUS, op. cit.

23 ARTE nova e curiosa para conserveiros, confeiteiros e copeiros (1788). Estudo e atualização do texto: Isabel M. R. Mendes Drumond Braga. Sintra: Colares, 2004

24 LAURIOUX, Bruno. Cozinhas Medievais, séculos XIV e XV. In: FLANDRIN, Jean-Louis; MONTANARI, Massimo (Orgs.). História da Alimentação. São Paulo: Estação Liberdade, 1998. p. 450. 
artista pela gastronomia e suas experiências culinárias em tavernas florentinas, na juventude, assim como suas estadias nas cozinhas das cortes dos Sforza e de Francisco I da França, como mestre de festejos e banquetes na primeira, levaram os editores a considerarem essas anotações de receitas como prováveis fragmentos dos cadernos de anotações de Leonardo, perdidos após a sua morte. $^{25}$

A autenticidade da autoria dessas receitas não interessa ao propósito deste estudo, mas sim seu significado enquanto "um tratado de gastronomia, considerado também um guia de urbanidade e um manual de usos e costumes" do início da Idade Moderna, como observou José Carlos Capel na “Apresentação" dessa obra. ${ }^{26}$ Realidade ou ficção, as Notas de cocina de Leonardo da Vinci, apesar do tom pitoresco, apresentam indícios de uma culinária típica do período no qual o artista viveu: pratos muito condimentados, grande consumo de carnes e sopas, ausência de batata e de tomate, além de pouco açúcar, sendo o mel o adulcorante por excelência, embora houvesse cultivo de cana-de-açúcar na Sicília.

Algumas anotações são, muitas vezes, desconexas, outras jocosas e as receitas podem, até, ser consideradas anedóticas. Mas há referências a construções de equipamentos engenhosos para uma suposta nova cozinha de Ludovico Sforza, bem como a preocupação com a higiene e a fumaça dos fogões no ambiente de trabalho, questões que poderiam realmente interessar ao famoso artista. O receituário tampouco se distancia do espírito da época, ao conter observações sobre medicina e dietética, "já que os tratados de cozinha deviam indicar as propriedades medicinais dos pratos e alimentos". ${ }^{27}$ Entretanto, são as receitas de doces e, especialmente, de conservas que importam destacar no momento.

Em um total de quase oitenta receitas, uma parcela muito reduzida refere-se aos frutos e aos pratos doces. $\mathrm{O}$ açúcar aparece raramente e, mesmo assim, como acabamento, polvilhado sobre os alimentos salgados. Os frutos, quando presentes, compõem os pratos salgados: sopa de castanha ou de uvas, ameixas sobre as carnes. ${ }^{28} \mathrm{O}$ destaque, em termos de doces, fica por conta de uma única receita de marmelada, alguns comentários sobre o marzipan, além de uma escultura monumental, na forma de um castelo, que Leonardo teria

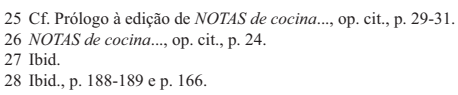


fabricado para as bodas de seu senhor, a qual teria sido totalmente consumida pelas formigas e ratazanas na noite anterior ao banquete... ${ }^{29}$

Quanto ao marzipan, feito com mel, amêndoas e clara de ovos de acordo com o suposto registro de Leonardo, seria fabricado pelas freiras de Santa Corona "para minhas esculturas". Mas para desgosto do artista, seus estudos realizados em marzipan eram comidos aos pedaços por Ludovico e sua corte. ${ }^{30}$ Resta a comentar, assim, a única receita de doce: marmelada de couve, que era feita com mel e a partir de técnicas presentes em muitos outros livros de cozinha editados posteriormente. A receita era da cozinheira de Leonardo, "ideal para acompanhar pratos de carne", mas que, segundo o artista, seria um acompanhamento "totalmente inútil", do qual jamais provaria... ${ }^{31}$

De conteúdo mais histórico e plausível para a época é o menu apresentado para um banquete na corte dos Sforza, no qual estão representados pratos de carnes diversas (embutidos de porco, gansos, capões), macarrões, pastelões e marzipam de Siena. ${ }^{32}$ Portanto, apesar de todo o tom pitoresco do livro, é possível resgatar nas receitas alguns traços da culinária do fim do período medieval.

\section{$* * *$}

A obra de Nostradamus, Traité des Fardements e Confitures (1552), por sua vez, não tem nada de ficcional, sendo considerada um dos primeiros tratados sobre o assunto e que atingiu, no espaço de trinta e cinco anos, doze edições. O receituário é resultado das pesquisas de Nostradamus sobre plantas e alquimia, assim como de sua prática da medicina. A intenção maior do tratado é ensinar a fabricar conservas, buscando revelar as virtudes dos doces de frutos para a prevenção ou cura de enfermidades, como se observa no comentário do próprio autor:

Muitos haverá que nem sempre têm à mão um boticário, ou um merceeiro onde possam comprar doces de frutos, sem contar que na maior parte das vezes, caímos nas mãos de algum mestre, ou de um

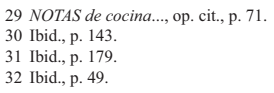


jovem aprendiz, que pensa saber muito, e que na maior parte das vezes não sabe nada, e estraga o doce, deixa queimar o açúcar ou o mel de tal forma que somos obrigados a deitá-lo fora.

E para fugir a tais inconvenientes que surgem com muita freqüência, leia bem o que se segue: "fará tanto melhor o seu doce de frutas e mais distintamente se seguir os meus conselhos. Não encontrará diferenças entre estes e as que trazem de Espanha ou de Itália". ${ }^{33}$

Infere-se, das palavras de Nostradamus, a existência de uma tradição medicinal ligada ao consumo de conservas, famosas já nessa época no sul da Europa, mas ausentes do suposto livro de cozinha de Leonardo. Foi, contudo, em Milão - território dos Sforza e senhores de Da Vinci - que Nostradamus teria conhecido um sábio em alquimia, o qual lhe revelou as virtudes dos doces de frutos. ${ }^{34}$

O receituário do célebre autor das Profecias apresenta trinta receitas de conservas, geléias e xaropes de frutos diversos. Muitas vezes ele indica as qualidades alimentícias e medicinais dos doces, assim como a forma de ingerilos. Mas quase sempre os doces não têm apenas utilidade farmacêutica. São alimentos agradáveis ao paladar, suaves e aconselhados para serem consumidos em qualquer oportunidade. No caso do doce de abóbora, por exemplo, informa: "Esse doce é bom para comer, embora diga respeito à medicina refrigerante. Come-se pela sua suavidade e para mitigar o calor exuberante do coração e do fígado". ${ }^{35} \mathrm{O}$ doce de alface, por sua vez, era ideal

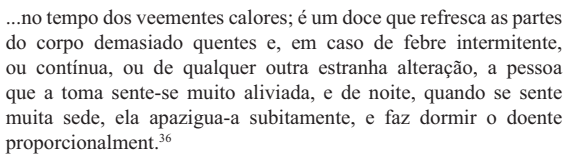
do corpo demasiado quentes e, em caso de febre intermitente, ou contínua, ou de qualquer outra estranha alteração, a pessoa que a toma sente-se muito aliviada, e de noite, quando se sente muita sede, ela apazigua-a subitamente, e faz dormir o doente proporcionalment. ${ }^{36}$

Já o doce de amêndoas e a geléia de marmelos propostos por Nostradamus podiam ser consumidos pelos doentes e pelos sãos. No caso do de

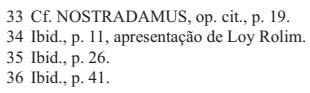


amêndoas, se fossem adicionadas especiarias, seria "indicado para acompanhar uma carne deliciosa", como acontecia com a receita de marmelada de couve do livro de Leonardo da Vinci. Um outro tipo de doce de marmelo tinha dupla utilidade: "para medicina confortativa e restritiva, e para comer a qualquer hora". 37

Fiel às concepções da medicina da época, Nostradamus informa, no capítulo XXIII, que o doce de casca de buglossa,

\footnotetext{
...a que os espanhóis chamam língua bovina é um doce estimulante que preserva a pessoa de definhar progressivamente ou de (se) tornar hidrópica e mantêm-na alegre e satisfeita. Afasta a melancolia, rejuvenesce o homem, retarda a velhice, dá boas cores ao rosto, mantém o homem saudável e impede o homem colérico de dar larga à sua cólera. ${ }^{38}$
}

Percebe-se, nesses comentários, que se tratava de um doce ideal para o restabelecimento do equilíbrio dos "humores", aos quais os indivíduos punham grande atenção na época.

A importância da obra de Nostradamus repousa, assim, na forma simples com que divulga seu saber e sistematiza as indicações terapêuticas das conservas de frutos. Por meio da utilização adequada de produtos disponíveis nas dispensas das casas mais remediadas, era possível confeccionar a maior parte das receitas prescritas, já que os doces presentes nesse receituário podiam ser feitos com mel ou mosto, além de açúcar. Em uma época em que o açúcar ainda era bastante caro e raro, o autor tornava acessível a um público amplo o que até então era consumido apenas pela elite. Este talvez seja o segredo de tantas edições do livro.

A Arte nova e curiosa para conserveiros, confeiteiros e copeiros e mais pessoas que se ocupam em fazer doces e conservas com frutas (1788) foi publicada em Portugal mais de duzentos anos após a primeira edição do

37 NOSTRADAMUS, op. cit., p. 69

38 Ibid., p. 77. 
Tratado de Nostradamus, em uma época, portanto, em que os conhecimentos medicinais das compotas de frutas estavam bem disseminados entre a população. O mesmo pode ser dito em relação ao uso do açúcar na alimentação e à arte da doçaria. Embora o termo "novo", existente no título do livro, pudesse chamar a atenção dos leitores, um simples folhear da obra revelaria aos profissionais experientes que se tratava de um artifício. No final do século XVIII, Portugal possuía uma indústria doceira desenvolvida e plenamente estabelecida há quase dois séculos. É certo que essa tradição culinária não se expressava no reduzido número de obras impressas, já que havia no mercado apenas dois livros de cozinha editados por cozinheiros afamados: o livro do português Domingos Rodrigues e o de Lucas Rigaud - um francês radicado em Lisboa -, datados respectivamente dos séculos XVII e XVIII. Em ambos, havia uma farta oferta de receitas de doces e de conservas de frutas. ${ }^{39}$ Por outro lado, havia ainda, à disposição dos interessados, um razoável número de obras francesas especializadas em "pâtisserie" circulando no mercado livreiro europeu. ${ }^{40}$

A novidade da obra ficava por conta das receitas de sorvete e também por ser o primeiro livro de receitas dedicado exclusivamente à doçaria publicado no país e, mesmo assim, com muitas receitas existentes no livro de Rigaud, cuja primeira edição datava de apenas oito anos antes e era já um sucesso editorial, e continuaria sendo até o século XIX.

A questão a destacar, contudo, não é a originalidade da obra, como havia sido no caso do tratado de Nostradamus, mas exatamente o inverso: a confirmação da importância desse setor na alimentação portuguesa, a ponto de se acreditar em um público leitor especializado (confeiteiros) ou mesmo mais difuso, dada a presença obrigatória dos doces nos banquetes da nobreza e nas refeições das camadas médias e altas. O que se observa, ainda, é que se trata de uma obra de culinária ou de gastronomia e não de um tratado médico ou de dietética como a de seu antecessor, o que indica mudanças nas práticas alimentares e o gosto pelos alimentos doces. Tampouco se nota a preocupação dos contemporâneos de Leonardo da Vinci com a higiene e a antiga dietética. Como lembrou Jean Louis Flandrin,

39 RODRIGUES, Domingos. Arte de cozinha (1680). Lisboa: Imprensa Nacional/Casa da Moeda, 1987; RIGAUD, Lucas. Cozinheiro moderno ou nova arte de cozinha (1780). Sintra: Colares, 1999. 40 FLANDRIN; MONTANARI, op. cit., p. 551. 


\begin{abstract}
...nos séculos XVII e XVIII, com a desculpa de um gosto novo, as preocupações higiênicas tendem a desaparecer e todas as referências à antiga dietética se apagam. Os cozinheiros e gastrônomos só sabem falar de harmonia dos sabores e esquecem, de resto que os sabores eram até então ligados tanto a eles como aos médicos. ${ }^{41}$
\end{abstract}

A obra apresenta 162 receitas de doces, nas quais predominam os "preparados pequenos", como observou Isabel Drumond Braga, entre eles biscoitos, broas, farteis e pastéis e uma grande variedade de doces de frutos. Em menor quantidade, registram-se as receitas de "doces de colher" (doces pastosos), à base de ovos e típicos da doçaria conventual portuguesa, bem como os "doces de bacia" (bolos e tortas). ${ }^{42} \mathrm{O}$ livro sugere, assim, ser uma compilação do que havia de mais tradicional e característico na confeitaria e conservaria nacionais e, por isso mesmo, apresenta grande valor para a História da Alimentação, permitindo comparações com os livros editados anteriormente (portugueses ou não) e com os cadernos de receitas das religiosas, os quais sobreviveram ao tempo e à gordura das cozinhas. A sua publicação atesta o desenvolvimento de um segmento específico do setor da edição e também o significado social e simbólico que o doce adquirira no século XVIII, embora o autor tenha insistido em não se identificar, negando-se, inclusive, a dirigir algumas palavras a seus leitores.

No caso das conservas de frutas, algumas das informações sobre saúde disponíveis na obra de Nostradamus são reafirmadas, mas as receitas não possuem mais a preocupação com a natureza dos alimentos e sua disgestibilidade, típica da classificação baseada nos sabores frios e quentes. Os ensinamentos técnicos sobre a arte de conservar, por sua vez, talvez não sejam tão detalhados quanto os de Nostradamus, mas é certamente nesse setor que a obra se destaca ao permitir a avaliação, ao longo do tempo, das práticas alimentares, do modo de cozinhar e dos equipamentos de cozinha.

41 FLANDRIN; MONTANARI, op. cit., p. 548.

42 Cf. ARTE nova e curiosa..., op. cit., p. 13, prefácio de Isabel Dumond Braga. 


\section{Técnicas e procedimentos da arte de conservar os frutos}

Entre o final do século XV, época do suposto registro da marmelada de couve nas anotações de cozinha de Leonardo da Vinci, e o século XVIII, muitas coisas mudaram nas cozinhas das grandes casas européias, mas no que tange à arte da conservaria, o princípio básico de preservar os frutos em caldas doces (feitas com mel ou açúcar) pouco mudou. As alterações ficam por conta de produtos novos, dos utensílios de cozinha que foram aprimorados e da forma de servir os doces e compotas, já que o ritual das refeições, o serviço de mesa e as normas de etiqueta passaram por transformações intensas entre o início e o final da Idade Moderna.

A grande revolução no campo da doçaria e, por extensão, na arte de conservar os frutos foi, certamente, a adoção do açúcar de cana como substituto do mel e, com ele, a difusão da indústria conserveira e doceira. Embora a utilização do açúcar refinado não fosse ainda totalmente dominante no século XVIII, haja vista a indicação da necessidade de clarificar o açúcar em muitas das receitas de conservas apresentadas na Arte nova e curiosa para conserveiros, o açúcar de cana tornou-se o produto por excelência da arte de fazer doces e conservas de frutos. Quando o produto refinado era indispensável ao sucesso da receita, havia a necessidade de especificações do tipo: "açúcar da Ilha da Madeira" ou "açúcar em pó". 43

A marmelada de couve do final do século XV era, portanto, feita com mel (metade do peso da couve), já as conservas de frutos prescritas por Nostradamus podiam ser feitas com mel, mosto ou açúcar de cana, o que indica bem a transição importante, mas paulatina, de substituição de um produto por outro. ${ }^{44}$ Embora no tratado do século XVIII poucos doces fossem ainda confeccionados com mel, o açúcar era "liquificado" de modo a atingir consistências semelhantes à do tradicional adulcorante. Só depois de adquirido o "ponto" certo (de cabelo, de espadana, de espelho e muitos outros) a calda de açúcar deveria ser adicionada à mistura de ovos, à farinha ou às frutas. Estas, na maior parte das vezes, já deveriam estar cozidas ou pré-cozidas no

43 Na receita de marmelada vermelha de açúcar em pó, pode-se ler:"A seis arráteis de açúcar da Ilha da Madeira pisados deitam quatro de marmelos crus... Cf. ARTE nova e curiosa..., op. cit., p. 41.

44 Nostradamus fornece a receita para a obtenção do mosto (líquido obtido da uva antes de terminada sua fermentação), o qual, adicionado a uvas bem maduras, proporcionava uma calda que, fervida e coada, servia como adoçante para a fabricação de conserva de fruta e, segundo o autor, "ficava tão bem e louvável com mosto como se tivesse sido feita com açúcar..." Cf. NOSTRADAMUS, op. cit., p. 35-37. 
momento de receber a calda doce, como se observa na receita de perada, que levava "quatro arráteis de açúcar clarificado em ponto grosso", o qual, depois de esfriado um pouco, "lhe deitarão sete arráteis de pêras mal pesadas, cozidas primeiro..."45

O processo de conservar os frutos consistia, assim, na adição de grandes quantidades de calda doce ao produto a ser confeccionado, devendo esta ser diariamente escoada e renovada. Tratava-se de um procedimento longo e trabalhoso, que começava com os cuidados com os frutos (descascar, lavar, retirar caroços e sementes, cortar, cozinhar), o qual só seria concluído após os frutos e as caldas passarem por vários cozimentos, sendo retirados e recolocados em tachos com extremo cuidado e controle dos pontos de cozedura. Apenas na última etapa adicionavam-se as especiarias como o cravo-da-índia, a canela e o almíscar. ${ }^{46}$

Comparando-se os processos de confecção de conservas de frutos divulgados no tratado de Nostradamus com aqueles disponíveis no livro de receitas do século XVIII, observa-se que a grande diferença entre eles repousa no tempo de preparação das conservas. No tratado do século XVI, uma conserva de casca de laranjas, por exemplo, poderia levar até um mês para ser feita. A mesma conserva no livro do século XVIII tomava dez dias de trabalhos e atenções. Mergulhados em caldas de mel, de mosto ou de açúcar, tudo indica que os frutos iam ficando doces e adquirindo consistência com o passar do tempo e das várias cozeduras e repousos. É possível, portanto, que a aparente "rapidez" da confecção da conserva do doceiro português estivesse relacionada à qualidade do adoçante utilizado: um açúcar mais puro e concentrado do que o consumido no tempo de Nostradamus e mais doce

45 NOSTRADAMUS, op. cit., p. 33

46 A receita de perinhas em conserva existente no receituário do século XVIII ilustra bem a técnica de conservar: "Aparem as peras e as vão lançando na água, porque se não façam negras, e postas a cozer em um tacho de água e como ferverem passem-nas com um alfinete grande para ver se estão cozidas e como se entender que o estão as vão tirando e lançando em um alguidar de água fria e as vão lavando e passando a outro alguidar de água e como estiverem bem lavadas em três ou quatro águas, as metam nos atanadores e lhe lancem por cima uma pouca de água quente e as deixem assim estar enquanto se clarifica o açúcar. E como o estiver escorram a água às pêras e lancem-lhe o açúcar, que fiquem bem cobertas, ao outro dia escorram o açúcar no tacho e desse-lhe uma fervura e isto vão fazendo quatro ou cinco dias, indo-lhe acrescentando o açúcar de modo que andem sempre cobertas e assim continuando isto nove dias, no fim deles fervem as pêras na conserva e no mais açúcar que lhe for necessário e lancem-lhe o âmbar que quiserem e como ferver as tiram e põem em alguidares e deles se vão metendo nas panelas e se the lança açúcar groso de modo que fiquem cobertas." Cf. ARTE novae curiosa..., op. cit., p. 33-34. Cabe lembrar que o processo é semelhante ao das receitas apresentadas no tratado de Nostradamus. 
do que o mel ou o mosto. Afinal, como ele próprio observou em uma de suas receitas de doce de laranja:

É certo que quanto mais o doce repousar, tanto melhor e mais adocicado ficará, pois o azedume que as laranjas possuem, quando mergulhadas no açúcar ou no mel durante alguns dias, adocica-se, e o seu sabor torna-se melhor e mais delicado. ${ }^{47}$

Apesar da diferença no adoçante utilizado, as receitas existentes nos dois tratados apresentam semelhanças, quer nos frutos utilizados, que permanecem praticamente os mesmos (laranjas, limões, ginjas, marmelos, abóboras e pêras), quer nas etapas e procedimentos de confecção (cozer o fruto, adicionar a calda, deixar repousar, escorrer e tornar a adicionar uma nova calda). É bem provável que o autor anônimo do tratado setecentista tenha se inspirado na obra de Nostradamus ou em outras compilações de receitas de conservas que remontavam, de alguma forma, às receitas do famoso autor das Profecias, já que, em geral, os livros de cozinha se inspiravam em um modelo anterior, muitas vezes datado de alguns séculos. ${ }^{48} \mathrm{O}$ que se observa, portanto, em termos de técnica, é a existência de uma "receita de base" - como enfatizou Jack Goody ao analisar a culinária inglesa do mesmo período -, a qual, modificada e adaptada a outros ingredientes, poderia resultar em novos sabores, novos doces e novos produtos a serem conservados. ${ }^{49}$

No Tratado da maneira de fazer doces de frutos (século XVI), por exemplo, não há registro de conservas de pêssegos, damascos e ameixas, as quais são abundantes no livro de cozinha do século XVIII. Neste, também se encontram compotas de frutos, cujo modo de preparar difere do das conservas, já que o fruto deveria ser cozido com o açúcar e servido quente, diretamente da panela, como registrou seu autor: "O doce de compotas é o que mais se usa nos banquetes por ir quente à mesa. Este doce nomeado compotas se costuma fazer de frutos de maçãs, como pêras". Seu preparo é diferente das conservas, pois os frutos são cozidos na calda do açúcar e quando estão "brandas se deitam no prato com a mesma calda e vai à mesa para beber água nevada sobre a dita compota. Desta compota se fazem todas as frutas..."

47 NOSTADAMUS, op. cit., p. 32

48 LAURIOUX, op. cit., p. 450.

49 Cf. GOODY, Jack. Receita, prescrição, experimentação. In: GOODY, Jack. Domesticação do pensamento selvagem. Lisboa: Presença, 1988. p. 157. 
O tratado do século XVIII utiliza ainda, em certas receitas, o recurso de secar os doces ao sol em tabuleiros ou caixas (doces secos), após serem cozidos com açúcar em calda, como no caso dos pêssegos cobertos, das ameixas cobertas ou da marmelada para caixa. ${ }^{50}$ Trata-se de uma outra forma de preservação dos frutos, embora apresente semelhanças com a técnica das conservas. Nostradamus, por sua vez, fornece uma receita de açúcar cristalizado, mas não de frutos cristalizados. Suas receitas são basicamente de conservas, xaropes e geléias, insistindo sempre na higiene dos potes que deveriam conter as conservas e no perfeito acondicionamento em recipientes bem fechados. ${ }^{51}$ Esses detalhes poderiam mudar sensivelmente a aparência e o gosto das conservas, bem como a forma de servir e consumir os doces de frutas.

Entre os séculos XV e XVIII, também ocorreram mudanças nos utensílios de cozinha. A cozinha do confeiteiro do século XVIII parece ser, sem dúvida, a mais equipada das citadas pelos três tratadistas estudados. Além de forno e fogão, havia alfinetes para verificar o cozimento das frutas (estes já mencionados por Nostrdamus, possivelmente devido à falta de garfos), panelas, balanças, tachos, palanganas (tabuleiros), peneiras, raladores, escumadeiras, facas, colheres, garfos, vasilhas de barro e metal, todos utilizados na fabricação das conservas. ${ }^{52} \mathrm{~A}$ do tempo de Leonardo, mesmo em se tratando de uma cozinha da nobreza, seria a mais discreta. Daí, talvez, o interesse do artista - registrado nas Anotações - em criar ele mesmo instrumentos de vários tipos para "limpar, picar, moer, descascar e cortar" os alimentos. O registro atribui a Leonardo, inclusive, a invenção do garfo de três dentes. ${ }^{53}$

$\mathrm{Na}$ época de Nostradamus, muito próxima à de Leonardo, panelas de ferro, pilão de madeira, caixas de madeira ou vidro e potes de barro eram os utensílios mais citados e praticamente não apareciam equipamentos específicos para a conservaria, como formas, tachos, joeiras, peneiras etc. Lembrando que até os pratos, copos e facas individuais eram ainda raros nos banquetes da nobreza do século XVI e que a comida era depositada sobre uma fatia de pão individualmente distribuída (no lugar de pratos), não é difícil imaginar o quanto os equipamentos de cozinha se multiplicaram em quase três séculos.

dias ao sol

50 ARTE nova e curiosa..., op. cit., p. 36,38 e 40 . Em todos os doces, deveriam permanecer dois

51 NOSTRADAMUS, op. cit., p. 81-82 - capítulo XXV, "Para fazer o açúcar cristalizado que será uma delicia".

52 Cf. ARTE nova e curiosa..., op. cit., p. 17.

53 NOTAS de cocina..., op. cit., p. 52-58. 
Eles acompanharam as transformações técnicas ocorridas na culinária, mas surgiram, sobretudo, para atender à arte de servir e de estar à mesa, que ganhou normas rígidas de conduta, em concordância com os códigos de civilidade e de bom tom que despontaram no período. ${ }^{54}$

Assim, de acordo com os três tratados de alimentação e dietética apresentados, podemos dizer que as conservas de frutas passaram de uma presença muito tímida nas refeições a um lugar de destaque na alimentação européia, ganhando, inclusive, status de arte independente, merecedora de obras específicas que as divulgassem. As Notas de cocina de Leonardo da Vinci, como outros livros de sua época, consistiam em um conjunto de observações de vários tipos, incluindo receitas de culinária. O tratado de Nostrdamus não desdenhava a importância do gosto agradável das conservas que poderiam ser consumidas em várias ocasiões, mas é, sem dúvida, um manual de saúde e dietética, preocupado com os efeitos terapêuticos dos alimentos, especialmente das conservas. Nele, encontram-se muitas receitas inexistentes no livro do século XVIII, como, por exemplo, a de doce de gengibre, cujas virtudes eram indicadas às mulheres que, "devido à frieza da matriz, não podem conceber, e o sémem genital não se retém”. Esse doce era considerado muito apropriado também para os mais idosos "em estado de debilidade". ${ }^{55} \mathrm{O}$ mesmo se observa na receita de xarope rosado laxativo, o qual foi considerado pelo autor "de efeito magnífico", por "não causar qualquer tipo de embaraço, nem dar dores de cabeça" "nem de estômago", tendo o autor a oportunidade de prescrevê-lo a "pessoas delicadas e honradas". ${ }^{56}$

O autor anônimo do tratado do século XVIII não desconhecia os métodos para obter água rosada ou fazer açúcar rosado a partir do cozimento de rosas, como tampouco o valor medicinal de muitas das conservas que prescreveu. Sua obra, contudo, destinava-se a profissionais e a todos aqueles que desejassem aprender a arte nova e curiosa da doçaria e, portanto, não se referia aos poderes de cura da água rosada. Esta deveria ser utilizada para aromatizar e colorir os doces. ${ }^{57}$ Afinal, era a aparência e o gosto das conservas, bem como dos outros doces, o que lhe interessava destacar, a fim de entreter e deleitar os convivas.

54 Ver sobre o assunto: PILLA, Maria Cecília B. Amorim. A arte de receber - distinção e poder à boa mesa 1900-1970. Curitiba, 2004. Tese (Doutorado) - Universidade Federal do Paraná, especialmente o capítulo 1, p. 7-49; REVEL, Jacques. Os usos da civilidade. In: ARIĖS, Philippe; CHARTIER, Roger (Org.). História da vida privada. São Paulo: Cia. das Letras, 1986. v. 3, "Da Renascença ao Século das Luzes".

55 NOSTRADAMUS, op. cit., p. 51.

56 Ibid., p. 99-101.

57 Cf. ARTE nova e curiosa..., op. cit., p. 28-29. 
Apesar das muitas semelhanças existentes nas receitas de conservas dos três tratados analisados ou daquelas oferecidas nos diversos livros de cozinha da Idade Moderna, pode-se dizer, com Bruno Laurioux, que um livro não é mera repetição do outro ${ }^{58}$ É, portanto, nas suas diferenças e nuanças, assim como nas múltiplas leituras que eles proporcionam, que repousa a importância dos livros de cozinha para a História da Alimentação. No caso das conservas de frutos, é possível captar sua introdução nas práticas alimentares, suas origens terapêuticas, suas conquistas por novos espaços, as quais confirmam os valores simbólicos dos alimentos atribuídos pelas sociedades, mas, especialmente, as modificações que ocorreram no tempo. Este, sem dúvida, o mais importante instrumento de análise do historiador.

\section{Referências}

ALGRANTI, Leila Mezan. Os doces na culinária luso-brasileira: da cozinha dos conventos à cozinha da casa "brasileira", séculos XVII a XIX. Anais de História de Além-Mar, Lisboa, Universidade Nova de Lisboa, 2006. No prelo.

ARTE nova e curiosa para conserveiros, confeiteiros e copeiros (1788). Estudo e atualização do texto: Isabel M. R. Mendes Drumond Braga. Sintra: Colares, 2004.

BRILLAT-SAVARIN, Jean Anthelme. A fisiologia do gosto. São Paulo: Cia. das Letras, 1995.

CONSIGLIERI, Carlos; ABEL, Marilia. A tradição conventual na doçaria de Lisboa. Sintra: Colares, 1999.

FLANDRIN, Jean-Louis; MONTANARI, Massimo (Orgs.). História da Alimentação. São Paulo: Estação Liberdade, 1998.

GOODY, Jack. Receita, prescrição, experimentação. In: GOODY, Jack. Domesticação do pensamento selvagem. Lisboa: Presença, 1988.

NOSTRADAMUS, Michel. Tratado da maneira de fazer doces de frutos. Sintra: Colares, 2002.

NOTAS de cocina de Leonardo Da Vinci - la afición desconocida de um gênio. Buenos Aires: Planeta, 2001. (Temas de Hoy)

58 LAURIOUX, op. cit., p. 450 
NUNES, Naidea. Palavras doces - terminologia e tecnologia históricas e actuais da cultura açucareira: do Mediterrâneo ao Atlântico. Funchal: Centro de Estudos de História do Atlântico, 2003.

PILLA, Maria Cecília B. Amorim. A arte de receber - distinção e poder à boa mesa 1900-1970. Curitiba, 2004. Tese (Doutorado) - Universidade Federal do Paraná.

REVEL, Jacques. Os usos da civilidade. In: ARIÈS, Philippe; CHARTIER, Roger (Org.). História da vida privada. São Paulo: Cia. das Letras, 1986. v. 3, "Da Renascença ao Século das Luzes".

REVEL, Jean François. Um banquete de palavras - uma história da sensibilidade gastronômica. São Paulo: Cia. das Letras, 1996.

RIBEIRO, Emanuel. O doce nunca amargou... Doçaria portuguesa, história, decoração, receituário. Sintra: Colares, 1997.

RIGAUD, Lucas. Cozinheiro moderno ou nova arte de cozinha (1780). Sintra: Colares, 1999.

RODRIGUES, Domingos. Arte de cozinha (1680). Lisboa: Imprensa Nacional/Casa da Moeda, 1987.

SARAMAGO, Alfredo. Doçaria Conventual do Alentejo - as receitas e o seu enquadramento histórico. 4. ed. Sintra: Colares, 2000.

SOUSA, Gabriel Soares de. Tratado descritivo do Brasil em 1587. São Paulo: Cia. Editora Nacional, 1971.

STRONG, Roy. Banquete - uma história ilustrada da culinária, dos costumes e da forma à mesa. Rio de Janeiro: J. Zahar, 2004.

VIEIRA, Alberto. Canaviais, açúcar e aguardente na Madeira séculos $X V$ a XX. Funchal: Centro de Estudos de História do Atlântico.

WEBB, Marcus A.; CRAZE, Richard. O guia das plantas \& especiarias. Lisboa: Livros e Livros, 2000. 